\title{
Prediction and Analysis of Deposition Efficiency of Plasma Spray Coating Using Artificial Intelligence Method
}

\author{
Ajit Behera*, S. C. Mishra \\ Department of Metallurgical \& Materials Engineering, National Institute of Technology, Rourkela, India. \\ Email: ${ }^{*}$ ajit.behera88@gmail.com
}

Received January $18^{\text {th }}, 2012$; revised February $26^{\text {th }}, 2012$; accepted March $10^{\text {th }}, 2012$

\begin{abstract}
Modern industrial technologies call for the development of novel materials with improved surface properties, lower costs and environmentally suitable processes. Plasma spray coating process has become a subject of intense research which attempts to create functional layers on the surface is obviously the most economical way to provide high performance to machinery and industrial equipments. The present work aims at developing and studying the industrial wastes (Flay-ash, Quartz and illmenite composite mixture) as the coating material, which is to be deposited on Mild Steel and Copper substrates. To study and evaluate Coating deposition efficiency, artificial neural network analysis (ANN) technique is used. By this quality control technique, it is sufficient to describe approximation complex of inter-relationships of operating parameters in atmospheric plasma spray process. ANN technique helps in saving time and resources for experimental trials. The aim of this work is to outline a procedure for selecting an appropriate input vectors in ANN coating efficiency models, based on statistical pre-processing of the experimental data set. This methodology can provide deep understanding of various co-relationships across multiple scales of length and time, which could be essential for improvement of product and process performance. The deposition efficiency of coatings has a strong dependence on input power level, particle size of the feed material, powder feed rate and torch to substrate distance. ANN experimental results indicate that the projection network has good generalization capability to optimize the deposition efficiency, when an appropriate size of training set and network is utilized.
\end{abstract}

Keywords: ANN; Plasma Spraying; Deposition Efficiency; Power Level; Particle Size; Feed Rate

\section{Introduction}

The role of surface coatings has become increasingly demand for various engineering applications in industries because requirement of high efficiency and longer service life of the equipment [1-4]. Thermal spraying holds a unique position in the spectra of surface modification technologies because it can provide thick coatings over $100 \mu \mathrm{m}$ over a large area at a very high application rate compared with other coating processes such as PVD, CVD and electroplating [5,6].The conventional plasmaspraying process is commonly referred to as air or atmospheric plasma spraying (APS). In this APS technology, the coating materials used with well-defined melting point ranging from metallic and ceramic materials to polymeric material [7]. To generate the plasma, an inert gas typically argon or argon+ hydrogen mixture is superheated by a direct-current arc [8]. Plasma temperatures in the power heating region range from approximately $6000^{\circ} \mathrm{C}$ to $15000^{\circ} \mathrm{C}$, which are significantly above the melting point of any known material [7]. The materi-

\footnotetext{
*Corresponding author.
}

als in the form of powder mixture (Flay-ash+quartz+ illmenite powder composite) are injected into a hightemperature plasma flame. The powder mixture (size from $40 \mu \mathrm{m}$ to $100 \mu \mathrm{m}$ ) is then rapidly heated and accelerated to a very high velocity by the plasma flame, impacts the surface of the substrate material in the form of molten or semi-molten state and very quickly cools to form a high-quality coating [8,9-11]. The quality control of plasma spray technique generally considers the monitoring of the molten feedstock particle characteristics, deposited at the substrate surface i.e. to increase the coating efficiency [12]. The deposition efficiency is the main requirements of the coatings developed by plasma spraying. It is defined as the ratio of the weight of coating deposited on the substrate to the weight of the expended feedback. Deposition efficiency represents the effectiveness of the deposition process as well as the coatability of the powder under study [13]. In this decade, Mishra et al. attempt to spray different type of raw material and fly-ash mixture on metal substrates through plasma spraying and studied the behavior of coating 
deposition efficiency [14-17]. Plasma spraying process depends on the operating conditions, the desired properties of the final coating, etc. Besides the intrinsic material properties, the technical requirements for the plasma spray feedstock powders include good flowability and sprayability. They are greatly affected by the particle size, shape and morphology as well as particle size distribution [18]. Hence the coating deposition efficiency directly or indirectly depends on many other parameters during spraying, in which each one is inter-related with each other. ANN study and design of systems capable of perceiving their environment $\&$ taking actions maximizeing their chance of success and to increase deposition efficiency.

A neural network is a mathematical model processing system which is capable to relate input to output parameters and learning from data set through iteration, without requiring a prior knowledge on the relationships between the process variables [19]. This model can able to approximate various nonlinearities in the data series, among other models [20-22] and can give an appropriate optimized data output (Deposition efficiency).

\section{Experimental Procedure}

Mixture of Flay-ash, Quartz and illmenite used as a composite coating material on the Copper and Mild Steel substrates. Flay-ash, Quartz and illmenite mixture was taken with their weight percentage ratio of 60:20:20 and mechanically milled in a FRITSCH-Planetary ball mill for 3 hour to get a homogeneous mixture. This mixture used as feed stock for plasma spraying was first sieved and four different size i.e. $100 \mu \mathrm{m}, 80 \mu \mathrm{m}, 60 \mu \mathrm{m}$ and 40 $\mu \mathrm{m}$ are separated out. The substrate materials have dimensions of 1 inch diameter and $3 \mathrm{~mm}$ thickness. The substrate were grit blasted at a pressure of $3 \mathrm{~kg} / \mathrm{cm}^{2}$ using alumina grit to make the surface roughness $\sim 5.00$ Ra. After grit blasting substrates surface were cleaned by acetone and then immediately plasma spraying was carried out. The coating process made by using a $40 \mathrm{KW} \mathrm{dc}$ power supply plasma spray system at the Laser \& Plasma Technology Division, BARC, Mumbai. The plasma input power level was varied from $11 \mathrm{KW}$ to $21 \mathrm{KW}$. This is a typically atmospheric plasma spray process, which is working in the non-transferred arc mode. The injection of the powder from the torch nozzle directed perpendicular to the plasma flow and parallel to the torch trajectory. The torch was operated using argon (Ar) and Nitrogen $\left(\mathrm{N}_{2}\right)$ plasma mixture gas. The major subsystems of the set up include the power supply, powder feeder, plasma gas supply, plasma spraying torch, and substrate to torch distance controller, cooling water and spray booth. For cooling the system, a water cooling system used which is a four stage closed loop centrifugal pump, regulated at a pressure of $10 \mathrm{~kg} / \mathrm{cm}^{2}$ supply. Operating parameters used for coating deposition are given in Table 1. Flow rate of plasma gas (argon) and Secondary gas $\left(\mathrm{N}_{2}\right)$ are kept constant. Powder feed rate, Powder Size and Torch to base distance (TBD) are varied with respect to increase in power level.

\section{Artificial Neural Network}

Artificial neural network is a technique that involves database training to predict property-parameter (output) evolutions, more quickly $[23,24]$. This section presents the database construction, implementation protocol and a set of predicted results for coating deposition efficiency [25]. ANN of simple processing elements (neurons) typically organized in layers (input layers, hidden layers and output layers) shown in Figure 1. Each neuron receives multiple inputs in proportion to their connection weights and generates a single output which may be propagated to several other neurons [26]. A software package NEURALNET for neural computing developed, by using back propagation algorithm as the prediction tool for output (coating deposition efficiency) [27]. The procedure to find out the deposition efficiency for plasma spraying is described as:

Step 1. Input training parameters: Among all data set, $75 \%$ data set are taken as Input (parameter set includes V, I, Torch to base distance, powder federate and powder size and deposition efficiency) to train and define the ANN architecture.

Step 2. Input testing parameters: In this step, remains $25 \%$ of data set enters by excluding its output parameter (deposition efficiency) value.

Step 3. Adjust the number of neuron for layers for training.

Step 4. Training process: Execute the training set builder program, in order to build the training set for the

Table 1. Operating parameters during deposition of Flyash+ quartz+ illmenite coatings.

\begin{tabular}{ll}
\hline Operating parameters & values \\
\hline Plasma arc current & $270,300,400 \& 420 \mathrm{Amp}$ \\
Arc voltage & $40,45 \& 50$ volt \\
Torch input power & $11,15,18 \& 21 \mathrm{KW}$ \\
Plasma gas(argon) flow rate & $28 \mathrm{IPM}$ \\
Secondary gas(N2) flow rate & $3 \mathrm{IPM}$ \\
Carrier gas(Ar) flow rate & $12 \mathrm{IPM}$ \\
Powder feed rate & $12,15 \& 18 \mathrm{gm} / \mathrm{min}$ \\
Powder Size & $40,60,80 \& 100 \mu \mathrm{m}$ \\
Torch to base distance(TBD) & $100,120,140 \mathrm{~mm}$ \\
\hline
\end{tabular}




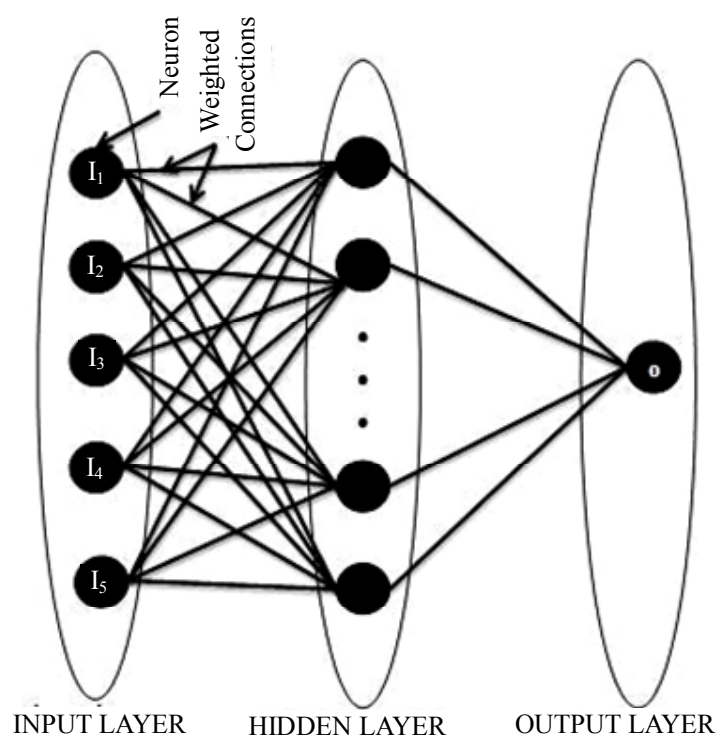

Figure 1. Architecture of ANN.

learning of ANN.

Step 5. Test process: After training process, the output value of above $25 \%$ data set is observed.

Step 6. Error percentage calculation: in this step, the ANN deposition efficiency of testing data is compare with that of experimental data. The test error is an important quantity since it can be viewed as an estimate of the generalization error. This should not be too large compared to training error, in which case one must suspect that the network is over-fitting the training data [28].

Step 7. If there is a greater error percentage, then set the neuron number of Step 3 and execute the evaluator in order to find the optimal values.

Step 8. Prediction for experimental input: Again the whole experimental input data enters to find out the ANN predicted deposition efficiency.

Step 9. Compare the neural network response of step-5 and the optimal solution of step-7 in order to evaluate the problem recognition capability of neural network.

There are no fixed rules for developing an ANN, but through a general framework it can be followed based on previous successful applications in engineering. The aim of an ANN is to normalize an input-output relationship of the form of:

$$
\mathrm{y}^{\mathrm{m}}=f\left(\mathrm{x}^{\mathrm{n}}\right)
$$

where, $\mathrm{x}^{\mathrm{n}}$ is an $\mathrm{n}$-dimensional input vector represents variable parameters $x_{1}, \cdots x_{i}, \cdots x_{n}$ and $y^{m}$ is an m-dimensional output vector represents the resulting variables $\mathrm{y}_{1}, \cdots \mathrm{y}_{\mathrm{i}}, \cdots \mathrm{y}_{\mathrm{m}}$. In plasma spray modeling, values of $\mathrm{x}$ may be Current, Voltage, Torch-to-base distance, powder federate and powder size.

\section{Results and Discussion}

A software package NEURALNET is used for neural computing, developed by Rao and Rao [27], which can predict the coating deposition efficiency. Operation of database undergoes between three categories step i.e. input, hidden layer and out-put layer which are graphically present in Figure 1. About 12 data sets including voltage, current, torch to base distance, powder feed rate, powder size are taken to train the neural network used for predicting coating deposition efficiency. With varying number of neurons in the hidden layer are tested at constant cycles, learning rate, error tolerance, momentum parameter and noise factor and slope parameter. Based on least error criterion, one structure given in Table 2 is selected for training of the input-output data. The learning rate is varied in the range of $0.002-0.100$ during the training of the input-output data. The network optimization process (training and testing) is conducted for $10,000,000$ cycles for which stabilization of the error is obtained. The number of cycles selected during training is high enough so that the ANN models could be rigorously trained. Neuron numbers in the hidden layer is varied and in the optimized structure of the network this number is 8 (for Copper) and 6 (for Mild Steel).

\subsection{Predicted Deposition Efficiency Compare with Experimental Results Based on Different Feed Rate}

In Figure 2, there is a comparative study of ANN prediction value of coating deposition efficiency with that of experimental value for copper substrate. There are two comparison plot to confirm the error between ANN prediction and experimental. In plot $\left(a_{1}\right)$, the fly-ash+ quartz+illmenite powder mixture are deposited on copper substrate at $12 \mathrm{gm} / \mathrm{min}$ feed rate, $100 \mathrm{~mm}$ torch to base distance with varying the power level. In plot $\left(b_{1}\right)$, the powder mixture are deposited at $18 \mathrm{gm} / \mathrm{min}$ feed rate, $140 \mathrm{~mm}$ torch to base distance. As seen from the figure, the close agreement of the values of the coating deposi-

Table 2. Input parameters selected for training.

\begin{tabular}{ll}
\hline Input Parameters for Training & Values \\
\hline Error tolerance & 0.003 \\
Learning parameter(ß) & 0.002 \\
Momentum parameter( $\alpha$ ) & 0.002 \\
Noise factor (NF) & 0.001 \\
Maximum cycles for simulations & $1,00,00,000$ \\
Slope parameter (£) & 0.6 \\
Number of hidden layer neuron & 8 \\
Number of input layer neuron (I) & 5 \\
Number of output layer neuron (O) & 1 \\
\hline
\end{tabular}




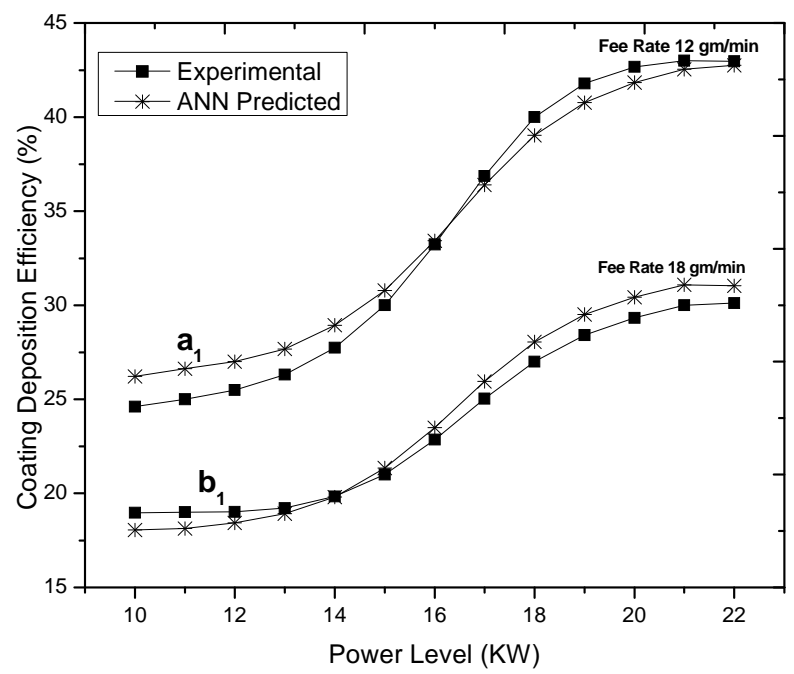

Figure 2. Comparison plot between ANN Prediction deposition efficiency and experimental value of Copper (plot $\left.a_{1}\right)$ at $12 \mathrm{gm} / \mathrm{min}$ feed rate and (plot $b_{1}$ ) at $18 \mathrm{gm} / \mathrm{min}$ feed rate (fly-ash+quartz+illmenite powder mixture are deposited on Copper substrate).

tion efficiency by the neural network and the experimental study clearly indicates that the model can be used for predicting the amount coating deposition efficiency. For Mild steel substrate the comparison plots are shown in Figure 3 by varying power level. In plot $\left(a_{2}\right)$, the powder mixture $12 \mathrm{gm} / \mathrm{min}$ feed rate, $100 \mathrm{~mm}$ torch to base distance. In plot $\left(b_{2}\right)$, the powder mixture are deposited at $18 \mathrm{gm} / \mathrm{min}$ feed rate, $140 \mathrm{~mm}$ torch to base distance.

\subsection{Comparisons between Mild Steel \& Copper Substrate in Account of ANN PREDICTED "Rate of Deposition Efficiency" Results}

Figure 4 shows the coating deposition efficiency for Copper and Mild Steel substrate. In each substrate it is clearly observe that by increasing the power level from $11 \mathrm{KW}$ by taking any of the feed rates ranging from 12 $\mathrm{gm} / \mathrm{min}$ to $18 \mathrm{gm} / \mathrm{min}$, the coating deposition efficiency increases up to a certain limit ( $\sim 19 \mathrm{KW})$ and further increase in power level, there is decrease in rate of deposition efficiency. These results can be clearly detected from the SEM figure of substrate deposited surface, which is shown in Figure 5. The image analysis of the splats on the substrate surface allows determining their size and shape factors versus the substrate nature, temperature [29]. There is a comparison SEM structure of deposition efficiency for Copper substrate at $18 \mathrm{KW}$, which is nearly highest deposition efficiency (shown in Figure 5(a)) with $21 \mathrm{KW}$, which leads to decreasing in "rate of deposition efficiency" (shown in Figure 5(b)). In $18 \mathrm{KW}$ power level there is uniform spreading of splats and there is less inter splat cavity. But when we go for 21

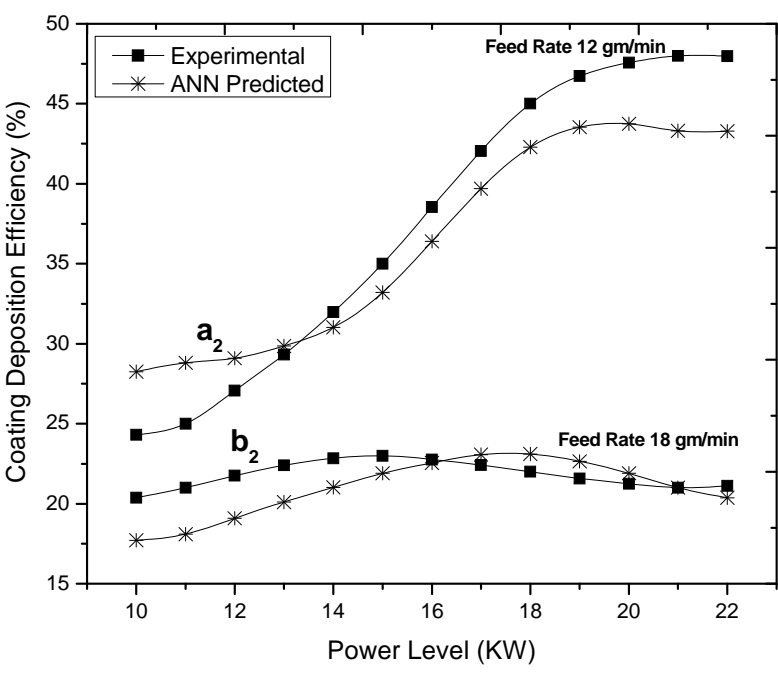

Figure 3. Comparison plot between ANN Prediction deposition efficiency and experimental value of Mild Steel (plot $a_{2}$ ) at $12 \mathrm{gm} / \mathrm{min}$ feed rate and (plot $b_{2}$ ) at $18 \mathrm{gm} / \mathrm{min}$ feed rate (fly-ash+quartz+illmenite powder mixture are deposited on Mild Steel substrate).

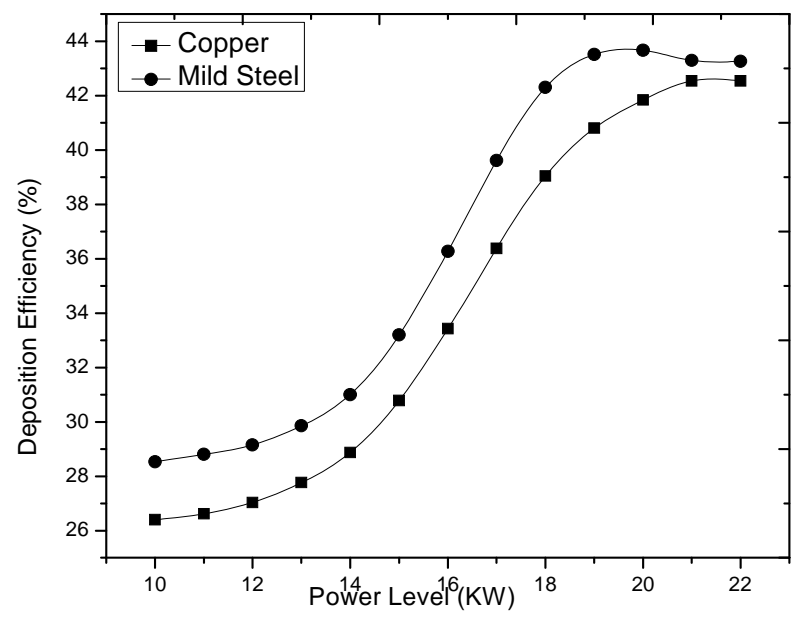

Figure 4. Comparison plot between ANN Prediction deposition efficiency for Copper and Mild Steel (fly-ash+quartz+ illmenite powder mixture are deposited at $12 \mathrm{gm} / \mathrm{min}$ feed rate).

KW power level, there is occurrence of more intersplat cavitations. At higher power level, more vaporization of powder generates and they spreads \& interconnect just before impact at the substrate surface, which is main cause for cavitations and decrease in rate of deposition efficiency. But in case of Mild steel substrate, the rate of deposition efficiency decreases larger than that of Copper substrate in the power level range from $18 \mathrm{KW}$ to $21 \mathrm{KW}$. The SEM microstructure of splats deposited on Mild steel substrate at $18 \mathrm{KW}$ and $21 \mathrm{KW}$ are shown in Figures 5(c) and (d) respectively. Here the additional parameter for decreasing deposition efficiency is its thermal conductivity. At higher power level particles gain higher 


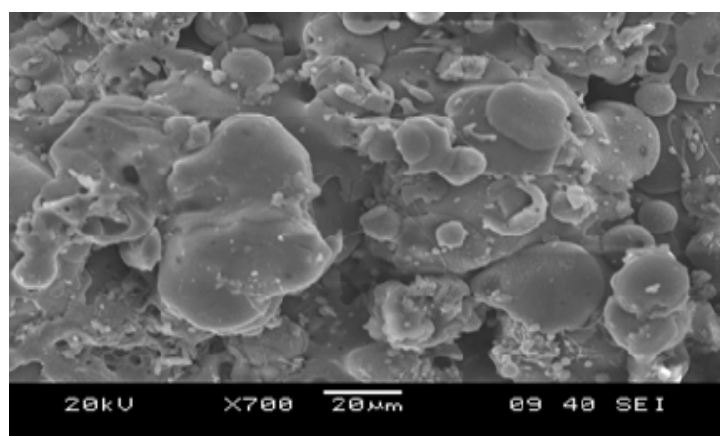

(a)

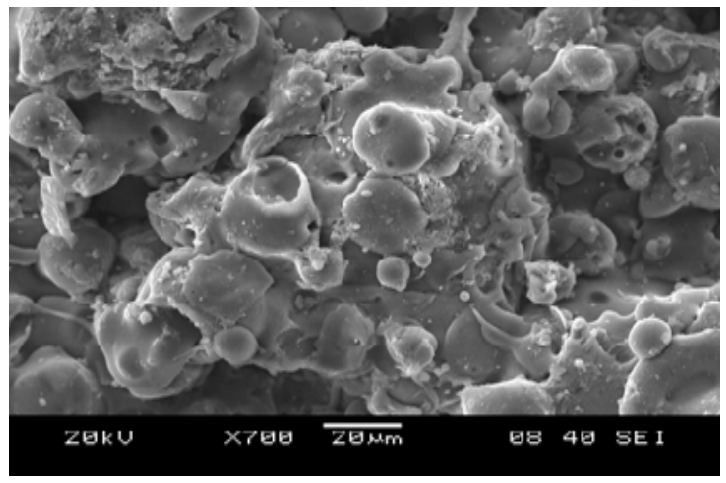

(b)

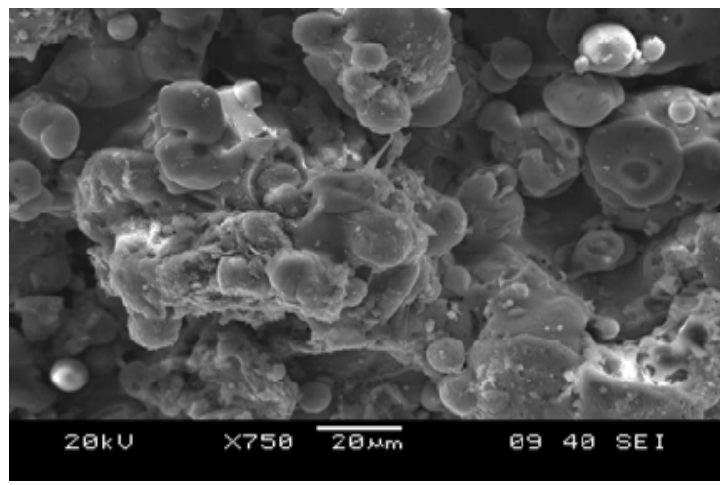

(c)

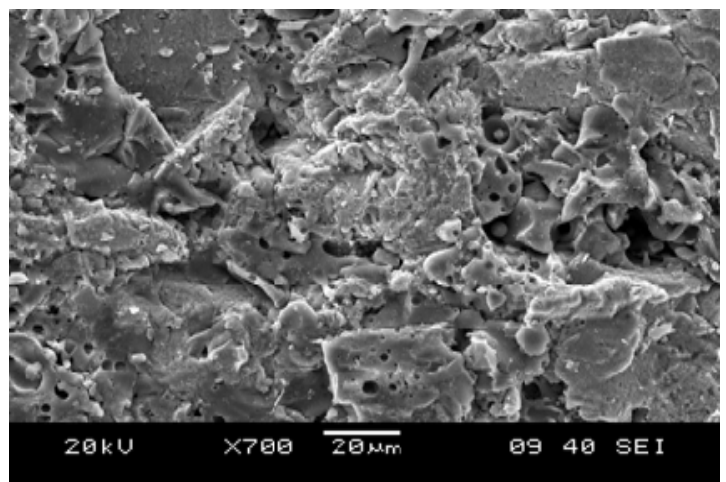

(d)

Figure 5. Surface morphology of Copper (a) at $18 \mathrm{KW}$ (b) at $21 \mathrm{KW}$ and surface morphology of Mild steel (c) at 18 $\mathrm{KW}$ (d) at $21 \mathrm{KW}$ (fly-ash+quartz+illmenite deposited as coating material on Copper \& Mild Steel substrates). energy in its molten state and at the time of impact on the Mild steel surface, it cannot transfer the thermal energy suddenly for which there is formation of some interspacing in between the layers and also with the Mild steel surface. The particle temperature and the splat evolution during its flattening and the splat temperature evolution during its cooling are given in Ref. [30-32]. The cooling time, is strongly linked to the thermal contact resistance between the impacting particle and the substrate which in term seems to depend on the wettability of the molten droplet [33].

\subsection{Prediction Results Based on Powder Size}

In Figure 6, only the feed rate parameter changed to 15 $\mathrm{gm} / \mathrm{min}$ and predicted deposition efficiency plotted with respect to power level by varying the powder size. In

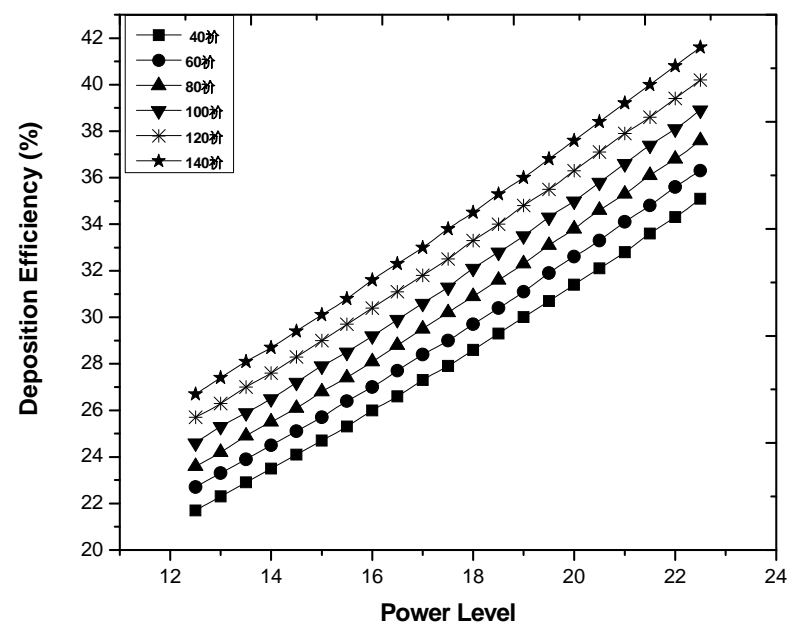

(a)

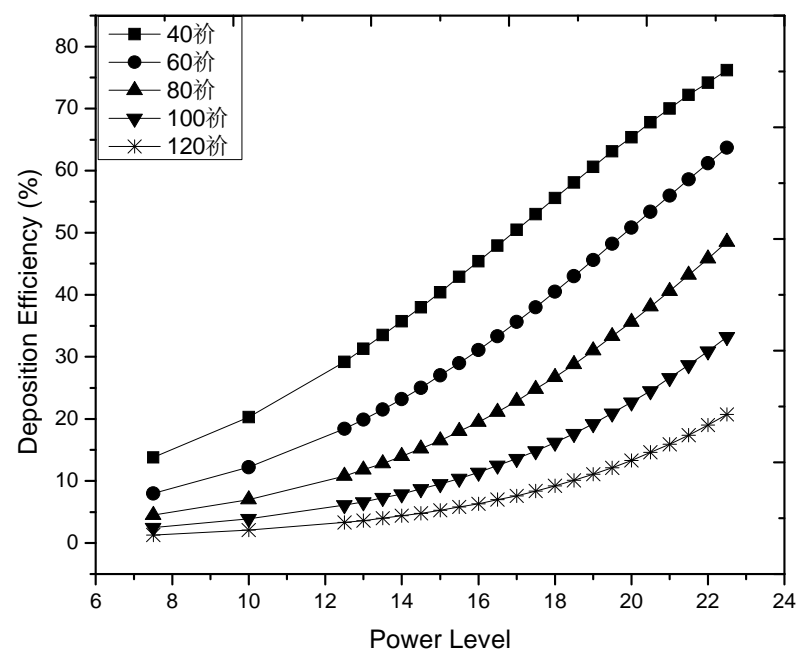

(b)

Figure 6. ANN Predicted deposition efficiency Vs Power level considering different powder size (a) for Copper \& (b) for Mild steel at $15 \mathrm{gm} / \mathrm{min}$ feed rate and $120 \mathrm{~mm}$ torch to base distance. 


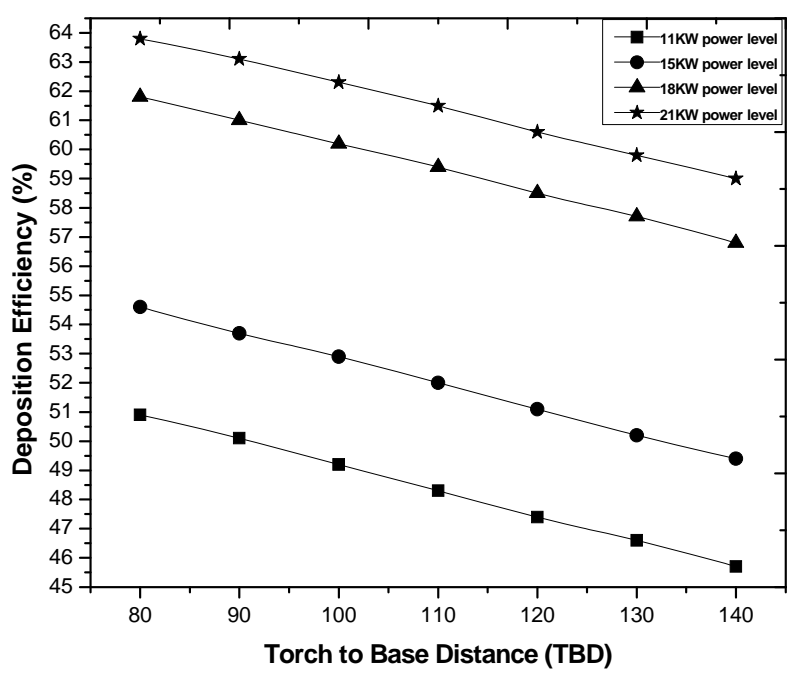

(a)

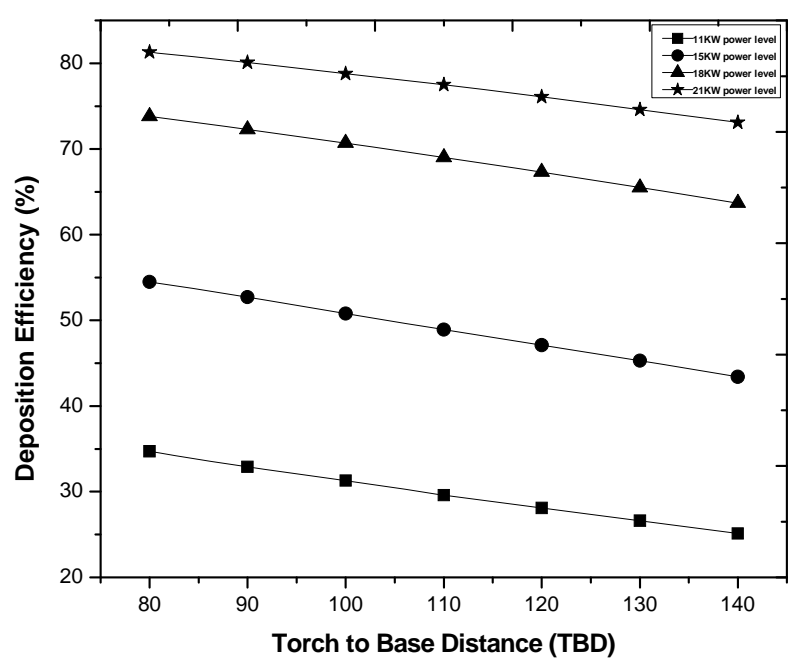

(b)

Figure 7. ANN Predicted deposition efficiency vs. TBD (a) for Copper and (b) for Mild steel at $40 \mu \mathrm{m}$ powder size.

Figures 6(a) and (b) it is observed that for any type of powder size (ranging from $40 \mu \mathrm{m}$ to $140 \mu \mathrm{m}$ ), the deposition efficiency increases with the power level. Because at the higher feed rate, vaporization of feedstock decreases (at $21 \mathrm{KW}$ power level). In case of Copper, higher value of coating deposition efficiency achieved by higher particle size than that of lower particle size. But for Mild steel, it shows a reveres trend i.e. the coating deposition efficiency decreases by increasing the powder size because of its lower thermal conductivity between larger particles and coating surface. But it is known that, the fine powder contained a significant fraction of fully densified particles, while larger particles were porous with different internal porosities [34]. But another case is the vaporization, which is more with fine powder than that of the powder with larger particle.

\subsection{Prediction Results Based on Torch to Base Distance}

In Figures 7(a) and (b) shows the different plots of ANN predicted deposition efficiency with respect to torch to base distance at different power levels for Copper and Mild steel respectively. During in flight traverse particles gain energy from the plasma and get melted. The heat and momentum transfer processes between the powder and the plasma influences the drag coefficient experienceed by the plasma on the powder [35] and also influences by the trajectory of the molten/semi-molten particle motion. From below figure it is clear that for 40 $\mu \mathrm{m}$ powder size, the deposition efficiency decrease with increase in spraying distance. By simultaneous increasing torch to base distance and power level, the deposition efficiency increases in both substrates. It is predicted that at $80 \mathrm{~mm}$ spray distance, the coating deposition efficiency will be higher at $21 \mathrm{KW}$ power level for both the cases.

\section{Results and Discussion}

The results indicate that neural network analysis can yield fairly accurate results and can be used as a practical tool in plasma deposition manufacturing process. The most popular advantage is its parallel mechanism; that is once an ANN is trained, it can provide the ability to solve the mapping problems much faster than conventional methods. In future engineering application, therefore, ANN may be the one to find out both high rate deposition capability and high functional values, with "sustainable", "viable" and "affordable" aspects of plasma spray coating.

\section{REFERENCES}

[1] F.-W. Bach, A. Laarmann and T. Wenz, "Modern Surface Technology," John Wiley \& Sons Ltd., Hoboken, 2007.

[2] M. Popescu, I. Bran, R. A. Roşu and C. Opriş, "Thermal Spraying-Interdisciplinary Domain", Annals Of the Oradea University, Oradea, 2011.

http://imtuoradea.ro/auo.fmte/files-2011-v2/TCM/Popesc u\%20Mihaela\%20L2.pdf

[3] S. Hasan, "Design Of Experiment Analysis Of High Velocity Oxy-Fuel Coating Of Hydroxyapatite," Master's Thesis, Faculty Of Engineering and Computing Dublin City University, Dublin, 2009.

[4] http://metalinkwear.com/thermalSpray/thermalSpray.html

[5] S. Kuroda, J. Kawakita, M. Watanabe and H. Katanoda, "Warm Spraying-A Novel Coating Process Based on High-Velocity Impact of Solid Particles," Science Technology of Advanced Materials, Vol. 9, No. 3, 2008, pp. 117, doi:10.1088/1468-6996/9/3/033002

[6] L. Pawlowsiki, "The Science and Engineering of Thermal Spray Coatings," 2nd Edition, Wiley, Hoboken, 2008.

[7] M. Zhang, X. X. Wang and J. R. Luo, "Influence of Plasma 
Spraying on the Performance of Oxide Cathodes," IEEE Transactions on Electron Devices, Vol. 58, No. 7, 2011, pp. 2143-2148. doi:10.1109/TED.2011.2141996

[8] J. R. Davis, Thermal Spray Society Training Committee and ASM International, "Handbook of Thermal Spray Technology,” ASM International, Ohio, 2004.

[9] J. Phillips, C. C. Luhrs and M. Richard, "Review: Engineering Particles Using the Aerosol-through-Plasma Method," IEEE Transactions on Plasma Science, Vol. 37, No. 6, 2009, pp. 726-739. doi:10.1109/TPS.2009.2016969

[10] P. Fauchais, "Understanding Plasma Spraying," Journal of Physics D: Applied Physics, Vol. 37, 2004, pp. 86-108. doi:10.1088/0022-3727/37/9/R02

[11] S. C. Mishra, A. Satapathy and M. Chaithanya, "Wear Characteristics of Plasma Sprayed Nickel-Aluminum Composite Coatings," Journal of Reinforced Plastics and Composites, Vol. 28, No. 23, 2009, p. 2931. doi:10.1177/0731684408094067

[12] C. Moreau, J. F. Bisson, R. S. Lima and B. R. Marple, "Diagnostics for Advanced Materials Processing by Plasma Spraying," Pure and Applied Chemistry, Vol. 77, No. 2, 2005, pp. 443-462. doi:10.1351/pac200577020443

[13] S. C. Mishra, et al., "Neural Network Analysis for Deposition of Nickel-Aluminide Coatings on Steel by Plasma Spraying," 21st National Symposium of Plasma Science Society of India Dec, MNIT, Jaipur, 2006.

[14] S. C. Mishra, et al., "Use of Fly-Ash for Plasma Spray Coatings: Mineral Processing, Recent Advances and Future Trend," Allied Publishers, New Delhi, 1995.

[15] S. C. Mishra, et al., "Plasma Spray Coating of Flyash Premixed with Aluminium Powder Deposited on Metal Substrates," Journal of Material Processing Technology, Vol. 102, 2000, pp. 9-13.

[16] S. C. Mishra, A. Satapathy, K. P. Sreekumar and P. V. Ananthapadmanabhan "Coatability of Redmud on Metal Substrates," DAE-BRNS Workshop on Plasma Surface Engineering, BARC, Mumbai, 2004.

[17] S. C. Mishra, A. Sahu, R. Das, A. Satapathy and S. Sen, "Microstructure, Adhesion, and Erosion Wear of Plasma Sprayed Alumina-Titania Composite Coatings," Journal of Reinforced Plastics and Composites, Vol. 28, No. 9, 2008, pp. 1099-1109. doi:10. 1177/0731684407087758

[18] T. Talako, A. Ilyuschenko and A. Letsko, "SHS Powders for Thermal Spray Coating," KONA Powder and Particle Journal, No. 27, 2009, pp. 55-72.

[19] A.-F. Kanta, G. Montavon, M.-P. Planche and C. Coddet, "Plasma Spray Process On-Line Control by Artificial Intelligence Methodology," Advanced Engineering Materials, Vol. 9, No. 1-2, 2007, pp. 105-113. doi: 10.1002/adem.200600215

[20] S. Guessasma, G. Montavon and C. Codde, "Neural Computation to Predict In-Flight Particle Characteristic Dependences From Processing Parameters in the APS Process," JTTEE5, Vol. 13, No. 4, 2004, pp. 570-585.

[21] J. R. Fincke, W. D. Swank, R. L. Bewley, D. C. Haggard, M. Gevelber and D. Wroblewski, "Diagnostics and Control in the Thermal Spray Process," Surface \& Coatings
Technology, Vol. 146-147, 2001, pp. 537-543.

[22] J. Wray and G. G. R. Green, "Calculation of the Volterra Kernels of Non-Linear Dynamic Systems Using an Artificial Neural Network," Biological Cybernetics, Vol. 71, 1994, pp. 187-195.

[23] C. C. Huang, Y. T. Chen, Y. J. Chen, C. Y. Chang, H. C. Huang and R. C. Hwang, "The Neural Network Estimator for Mechanical Property of Rolled Steel Bar," Proceedings of Fourth International Conference on Innovative Computing, Information and Control of IEEE, Kaohsiung, 7-9 December 2009, pp. 1216-1219. doi:10.1109/ICICIC.2009.361

[24] H. Cetinel, H. Ozyigit, E. Celik and B. Karlık, "Artificial Neural Network-Based Prediction Technique for Wear Loss Quantities in Mo Coatings," Wear, Vol. 261, No. 10, 2006, pp. 1064-1068. doi:doi:10.1109/ICICIC.2009.361

[25] S. Rajasekaran and G. A. V. Pai, "Neural Networks, Fuzzy Logic and Genetic Algorithms-Synthesis and Applications," Prentice Hall of India Pvtate Ltd., New Delhi, 2003.

[26] J. S Torrecilla, L. Otero and P. D Sanz, "A Neural Network Approach for Thermal/Pressure Food Processing," Journal of Food Engineering, Vol. 62, No. 1, 2004, pp. 89-95. doi:10.1016/S2060-8774(03)00174-2

[27] V. B. Rao and H. Rao, "C++ Neural Networks and Fuzzy Systems,” BPB Publications, New Delhi, 2000.

[28] A. Verikas and M. Bacauskiene, "Using Artificial Neural Networks for Process and System Modeling," Chemomotrics and Intelligent Laboratory Systems, Vol. 67, No. 2, 2003, pp. 187-191. doi:10.1016/S0169-7439(03)00093-5

[29] H. Zhang, "Theoretical Analysis of Spreading and Solidification of Molten Droplet during Thermal Spray Deposition," International Journal of Heat and Mass Transfer, Vol. 42, No. 14, 1999, pp. 2499-2508. doi:10.1016/S0017-9310(98)00364-0

[30] P. Fauchais, J. F. Coudert, M. Vardelle, A. Vardelle and A. Denoirjean, "Diagnostics of Thermal Spraying Plasma Jets," Journal of Thermal Spray Technology, Vol. 1, No 2, 1992, pp. 117-128. doi:10.1007/BF02659011

[31] D. Poulikakos, "Heat Transfer and Fluid Dynamics in the Process of Spray Deposition," Advance in Heat Transfer, Vol. 28, 1996, pp. 1-74. doi:10.1016/S0065-2717(08)70139-4

[32] K. Shinoda, T. Koseki and T. Yoshida, "Influence of Impact Parameters of Zirconia Droplets on Splat Formation and Morphology in Plasma Spraying," Journal of Applied Physics, Vol. 100, 2006, p. 6. doi:10.1063/1.2355446

[33] P. Fauchais and M. Vardelle, "Plasma Spraying: Present and Future," Pure \& Applied Chemistry, Vol. 66, No. 6, 1994, pp. 1247-1258.

[34] M. Vardelle, A. Vardelle, P. Fauchais, K.-I. Li, B. Dussoubs and N. J. Themelis, "Controlling Particle Injection in Plasma Spraying," Journal of Thermal Spray Technology, Vol. 10, No. 2, 2001, pp. 267-284.

[35] S. Kumar, V. Selvarajan, P. V. A. Padmanabhan, K. P. Sreekumar, "Characterization and Comparison between Ball Milled and Plasma Processed Iron-Aluminium Thermal Spray Coatings," Surface \& Coatings Technology, Vol. 201, 2006, pp. 1267-1275. 